\title{
Comparison of the Acid-phosphatase Staining and Polymerase Chain Reaction for Detection of Dirofilaria repens Infection in Dogs in Korea
}

\author{
Sang-Eun LEE ${ }^{1)}$, Kun-Ho SONG ${ }^{1)}$, Jianzhu LIU ${ }^{1)}$, Myung-Chul KIM ${ }^{2)}$, Bae-Keun PARK ${ }^{3)}$, Kyu-Woan CHO ${ }^{4)}$, \\ Atsuhiko HASEGAWA ${ }^{5}$ and Duck-Hwan $\mathrm{KIM}^{1) *}$ \\ ${ }^{1)}$ Laboratories of Veterinary Internal Medicine, ${ }^{2)}$ Veterinary Surgery, and ${ }^{3)}$ Veterinary Parasitology, College of Veterinary \\ Medicine, Chungnam National University, Daejeon 305-764, ${ }^{4}$ Laboratory of Veterinary Clinical Pathology, College of Veterinary \\ Medicine, Gyeongsang National University, Chinju 660-701, Korea and ${ }^{5}$ Department of Pathobiology, Nihon University School of \\ Veterinary Medicine, Fujisawa, Kanagawa, 252-8510, Japan
}

(Received 25 September 2003/Accepted 20 April 2004)

\begin{abstract}
This study was performed to compare acid-phosphatase staining with polymerase chain reaction (PCR) analysis for the diagnosis of Dirofilaria repens infection. The infection of D. repens was confirmed in Korean reared German shepherd dogs. Knott's tests were carried out for the detection of microfilaria in 543 Korean reared German shepherd dogs ( 255 females and 288 males). Eight y four of the $543 \mathrm{dogs}(15.5 \%)$ showed microfilaria-positive reactions with the modified Knott's test, and the test-positive microfilariae were then examined by both acid phosphatase staining and PCR analysis. Six $(7.1 \%)$ and $17(20.2 \%)$ of the 84 microfilaria-positive sam ples, by the Knott's tests were positive to D. repens by acid-phosphatase staining and in D. repens-specific PCR analysis, respectively. All samples found to be positive by the acid-phosphatase staining were also found to be positive by PCR analysis. Therefore, we conclude that PCR analysis $(20.2 \%)$ is more valuable for the diagnosis of D. repens infection than acid-phosphatase staining $(7.1 \%)(\mathrm{p}<0.001)$. KEY WORDS: acid-phosphatase staining, canine, Dirofilaria repens, PCR.
\end{abstract}

J. Vet. Med. Sci. 66(9): 1087-1089, 2004

Dirofilaria repens, a filarial parasite of candids, is transmitted by mosquitoes. The adult worms are observed mainly in the subcutaneous tissue of $\operatorname{dog} s$, and produce microfilariae that circulate in the blood stream of those dogs infected. These nematoda have been found in Italy [19], Israel [8], Nigeria [9], Greece [20] and Spain [1], and an increasing number of zoonotic infections due to the filaria have been reported from different parts of the world [12, 13]. Only one human case of $D$. repens infection has ever been detected in Korea. Canine infection with $D$. repens was first reported in Korea using acid-phosphatase staining [11]. D. repens infections in dogs have been associated with skin swelling and hyperpigmentation, subcutaneous granulomas containing adult worms and local pruritis [5, 9]. Examinations for its diagnosis include: blood smear evaluation for the presence of microfilariae, serology for the presence of antibodies reactive with $D$. repens in animals and PCR for detection microfilarial DNA. However, microfilariae of $D$. repens are difficult to discriminate from those of Dirofilaria immitis, as they have similar morphologies and movement under light microscopy. Acid-phosphatase staining of microfilariae was effectively used for the differentiation of Dirofilaria species [3,15], especially, D. immitis and D. repens [16]. Recently, polymerase chain reaction (PCR) analysis was reported to be highly sensitive and dependable diagnostic tool for D. repens infections [20]. Therefore, this study was performed to compare acid-phosphatase staining with the PCR analysis for the diagnosis of D. repens infections.

\footnotetext{
* Correspondence to: Kim, D-H., Laboratory of Veterinary Internal Medicine, College of Veterinary Medicine, Chungnam National University, Daejeon 305-764, Korea.
}

\section{MATERIALS AND METHODS}

Dogs and surveyed areas: Five hundred and forty three Korean reared German shepherd dogs (255 females and 288 males) were used in the present study. These dogs received no prophylaxis and treatment for dirofilariosis. The study was carried out in five different areas (Gyunggi, Gangwon, Chungnam, Jeonnam and Gyungnam provinces) in Korea (Fig. 1).

Modified Knott's test and acid-phosphatase staining: The modified Knott's tests [6] were performed for microfilaria detection on $5 \mathrm{~m} l$ blood samples collected from the cephalic vein of all the dogs. Fifteen microfilariae of one milliliter of blood were observed by the modified Knott's test. An acidphosphatase staining kit (Leucognost-SP ${ }^{\circledR}$, Merck, Germany) was used for the discrimination of microfilariae in this study [16]. Each microfilaria found was examined, according to its staining characteristics with acid-phosphatase under light microscopy [15].

DNA isolation: Two hundred microliters of whole blood was lysed in $0.1 \mathrm{M}$ Tris- $\mathrm{HCl}$ ( $\mathrm{pH} 8.0$ ), containing $1 \%$ SDS, $0.1 \mathrm{M} \mathrm{NaCl}$ and $10 \mathrm{mM}$ EDTA. The samples were then treated with proteinase $\mathrm{K}(100 \mu \mathrm{g} / \mathrm{ml})$, for $2 \mathrm{hr}$, at $55^{\circ} \mathrm{C}$. The DNA was extracted with phenol/chloroform, precipitated by ethanol, and then dissolved in $50 \mu \mathrm{l}$ TE buffer (10 $\mathrm{mM}$ Tris- $\mathrm{HCl}$ (pH 8.0) and $1 \mathrm{mM}$ EDTA). The DNA samples were stored at $4^{\circ} \mathrm{C}$ until required.

PCR analysis: The PCR primer set used was; 5'-CCGGTAGACCATGGCATTAT-3' (forward) and 5'-CGGTCTTGGACGTTTGGTTA-3' (reverse), which were those used in a previous studies [17]. PCR were performed in $100 \mu \mathrm{l}$ reaction volumes, containing $10 \mu l 10 \times$ PCR buffer, $3 \mu l 50$ 


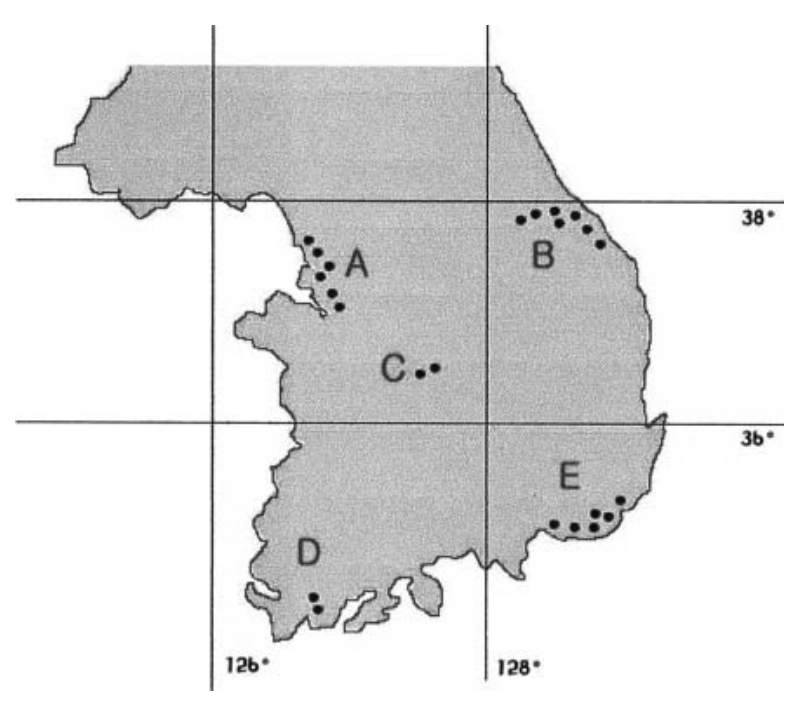

Fig. 1. Location of study area in Korea (A: Gyunggi province, B: Ganwon province, C: Chungnam province, D: Jeonnam province and $\mathrm{E}$ : Gyungnam province).

$\mathrm{mM} \mathrm{MgCl} 2,5 \mu l 1 \% \mathrm{~W}-1,200 \mathrm{mM}$ of each dNPT, $1.5 \mathrm{U}$ Taq polymerase, $25 \mathrm{pmol}$ of each primer and $10 \mu \mathrm{l}$ of template DNA. After an initial denaturation at $94^{\circ} \mathrm{C}$ for $5 \mathrm{~min}$, the reactions were subjected to 48 cycles of amplification, as follows; $30 \mathrm{sec}$ at $94^{\circ} \mathrm{C}, 30 \mathrm{sec}$ at $55^{\circ} \mathrm{C}$ and $25 \mathrm{sec}$ at $72^{\circ} \mathrm{C}$. Five microliters of the PCR products obtained were analyzed by $1.5 \%$ agarose gel electrophoresis, followed by ethidium bromide staining and photography.

The sensitivity (100\%) and specificity $(90.9 \%)$ for these D. repens-specific primers has been previously examined by Vakalis et al. [20].

Statistical analysis: The data in Table 2 were analyzed with a database (SPSS v. 10.0, K). The statistical analysis in Table 2 was carried out with the chi-squared test.

\section{RESULTS}

Modified Knott's test and acid-phosphatase staining: Eighty four of the 543 dogs $(15.5 \%)$ showed microfilariapositive reactions using the modified Knott's test (Table 1). The results of the acid-phosphatase staining from 84 microfilaria-positive samples are shown in Table 2. The microfilariae with one positive spot on the site of the anal pore were identified as $D$. repens, while those with two positive spots on the sites of the excretory pore and anal pore were identified as D. immitis. All of the stained sites appeared as spot-like red colors by the acid-phosphatase staining. Six $(7.1 \%)$ of the 84 samples that were microfilaria-positive by the Knott's tests were positive in the $D$. repens by acid-phosphatase staining (Table 2).

PCR: The results of the PCR analysis on 84 microfilariapositive samples are shown in Table 2 and Fig 1. The PCR with $D$. repens specific primers amplified a 246 bp product, indicating positive to $D$. repens, and negative to $D$. immitis.
Table 1. The results of modified Knott's test in 543 Korean reared German shepherd dogs

\begin{tabular}{lccc}
\hline Sex & No. (\%) & $\begin{array}{c}\text { No. of } \\
\text { microfilaria- } \\
\text { positive (\%) }\end{array}$ & $\begin{array}{c}\text { No. of } \\
\text { microfilaria- } \\
\text { negative (\%) }\end{array}$ \\
\hline Females & $255(100)$ & $45(17.6)$ & $210(82.4)$ \\
\hline Males & $288(100)$ & $39(13.5)$ & $249(86.5)$ \\
\hline Total & $543(100)$ & $84(15.5)$ & $459(84.5)$ \\
\hline
\end{tabular}

Table 2. Comparison of acid phosphatase staining and PCR for detection of D. repens infection in dogs

\begin{tabular}{lccc}
\hline & \multicolumn{3}{c}{ Acid phosphatase staining } \\
\cline { 2 - 4 } PCR & Positive & Negative & Total $(\%)$ \\
\hline Positive & 6 & 11 & $17^{\mathrm{a}}(20.2)$ \\
Negative & 0 & 67 & $67(79.8)$ \\
Total & 6 & 78 & $84(100)$ \\
\hline
\end{tabular}

a) Significant statistical difference $(p<0.001)$.

Seventeen $(20.0 \%)$ of the 84 samples that were microfilaria-positive by the Knott's tests were positive in $D$. repens-specific PCR analysis (Table 2).

Comparison between acid phosphatase staining and PCR analysis: All samples found to be positive by acid-phosphatase staining were also found to be positive by PCR analysis (Table 2). PCR analysis $(20.2 \%)$ is more valuable for the diagnosis of $D$. repens infection than that of acid-phosphatase staining $(7.1 \%)(\mathrm{p}<0.001)$.

\section{DISCUSSION}

D. repens is a mosquito-borne filaria, and a parasite of the subcutaneous tissue of domestic and wild carnivores, such as dogs, cats and foxes [6, 18]. The filaria is currently prevalent in Europe, mainly in the Mediterranean basin, subSaharan Africa and southern Asia [14]. Recently, canine infection of D. repens was confirmed in Korea, part of East Asia, for the first time [11]. D. repens is highly prevalent in river valleys and humid areas, and transmitted to dogs via many species of mosquitoes [13]. Mosquitoes of the genera Culex and Aedes are vectors, and the conditions for the establishment of their filaria exist in Korea [10, 11]. Factors that affect the transmission of $D$. repens include increases in mosquito population densities, mosquito species, mosquito fecundity and environmental temperature. Korea, as well as Japan, is located in a temperate zone, where it is hot and humid in the summer season, which is favorable for breeding of vectors [10]. Infection with the immature worms of D. repens has been found in humans, who develop nodules, mainly in subcutaneous tissue [12]. Humans are accidental hosts for the filarial, in whom the life cycle cannot be completed. Therefore, the parasites do not usually reach the adult stage and the microfilaremia is absent in humans. 
More than 270 cases of human dirofilariosis have been reported in European countries, and most were attributed to D. (Nochtiella) repens, and a few to D. immitis [13]. In Korea, Rim [17] first reported an immature Dirofilaria (Nochtiella) sp. in the abdominal cavity of a woman that had lived in Thailand for 8 months and Sri Lanka for 3 years prior to diagnosis; however, the country where she was infected by this worm could not be confirmed. In Japan, where no animal cases had been reported, only one human case (67-year old-male) of $D$. repens infection has been detected in Okinawa [12]. The infection with $D$. repens has been reported in Boxer, Doberman and Siberian Husky dogs by some researchers $[2,4,8]$. Korean reared German shepherd dogs participated in our study. These dogs were born in Korea and had never been taken abroad; so the life cycle of the filarial was completed in Korea. The living environments, as relayed from the owners, indicated more male dogs lived outdoors, due to their uses in definding of safety and property.

Lee et al. [11] reported that the prevalence of each species of microfilaria was $90.5 \%$ for $D$. immits, $5.4 \%$ for duplicate infection with $D$. immits and D. repens and $4.1 \%$ for Mixed infections with $D$. immits, D. repens and A. dracunculoides. The microfilariae in blood samples from the 84 Knott's test-positive German shepherd dogs, using acid phosphatase staining and PCR analysis were examined. One or two D. repens microfilariae per slide (about $20 \mu \mathrm{l}$ blood) were found in the blood smears in our study. Canine D. repens infection revealed skin swelling and hyperpigmentation, and subcutaneous granulomas, containing adult worms and local pruritis [5, 9]. In the present study, however, we could not find these symptoms of microfilaria in the PCR-positive dogs. The D. repens-specific PCR diagnostic method has become a valuable and highly dependable diagnostic tool. The sensitivity and specificity of the presently employed $D$. repens-specific DIR3/DIR4 primers were 100 and $90.9 \%$, respectively, and reliably and reproducibly detect the expected 246-bp long D. repens-specific PCR product in all the $D$. repens-infected dog blood samples [20]. Our results revealed that the incidence of $D$. repens by PCR $(20.2 \%)$ was higher than that of acid-phosphatase staining $(7.1 \%)(\mathrm{p}<0.001)$. All the samples that were found positive to the acid-phosphatase staining were also positive by PCR analysis. Therefore, it was concluded that the PCR analysis was more valuable for the diagnosis of $D$. repens infection than that of acid-phosphatase staining. PCR could be provisionally used in large scale epidemiological studies to estimate the prevalence of dirofilariosis in infected dogs, as the results were prompt and the technique could be simultaneously applied for many samples, with a high sensitive for diagnosis.

\section{REFERENCES}

1. Aranda, C., Panyella, O., Eritja, R. and Castella, J. 1998.
Canine filariasis: importance and transmission in the Baix Llobregat area, Barocelona (Spain). Vet. Parasitol. 77: 267-275.

2. Arnold, P., Deplazes, P., Ruckstuhl, H. and Fluckiger, M. 1994. Case report: dirofilariasis in a dog. Schweiz. Arch. Tierheilkd. 136: 265-269 (in German).

3. Balbo, T. and Abate, O. 1972. Histochemical differentiation of microfilariae of Dirofilaria immitis, Dirofilaria repens and Dipetalonema sp. Parasitologia 14: 239-244.

4. Baneth, G., Volansky, Z., Anug, Y., Favia, G., Bain, O., Goldstein, R.E. and Harrus, S. 2002. Dirofilaria repens infection in a dog: diagnosis and treatment with melarsomine and doramectin. Vet. Parasitol. 105: 173-178.

5. Bredal, W. P., Gjerde, B., Eberhard, M. L., Aleksandersen, M., Wilhelmsen, D. K. and Mansfield, L. S. 1998. Adult Dirofilaria repens in a subcutaneous granuloma on the chest of a dog. J. Small Anim. Pract. 39: 595-597.

6. Dissanaike, A. S. 1979. Zoonotic aspects of filarial infections in man. Bull. World Health Organ. 57: 349-357.

7. Ewing, S. A. 1986. Examination for parasites. pp. 385-386. In: Veterinary Clinical Pathology 4th ed., WB Saunders, Philadelphia.

8. Harrus, S., Harmelin, A., Rodrig, S. and Favia, G. 1999. Dirofilaria repens infection in a dog in Israel. Am. J. Trop. Med. Hyg. 61: 639-641.

9. Kamalu, B. P. 1991. Canine filariasis caused by Dirofilaria repens in southeastern Nigeria. Vet. Parasitol. 40: 335-338.

10. Lee, C. E., Cho, B. S., Lee, K. W., Kim, C. W., Lee, T.J. and Park, S.H. 1971. Insecta (IV). pp. 684-757. Illustrated Encyclopedia of Fauna \& Flora of Korea. Ministry of Education, Seoul (in Korean).

11. Lee, S. E., Song, K.H. and Kim, D. H. 2003. Prevalence study on the canine filariasis in Korea. Korean J. Vet. Res. 43: 517520 (in Korean).

12. MacLean, J.D., Beaver, P.C. and Michalek, H. 1979. Subcutaneous dirofilariasis in Okinawa, Japan. Am. J. Trop. Med. Hyg. 28: $45-48$.

13. Muro, A., Genchi, M., Cordero, M. and Simon, F. 1999. Human Dirofilariasis in the European Union. Parasitol. Today 15: 386-389.

14. Pampiglione, S., Canestri, Trotti, G. and Rivasi, F. 1995. Human dirofilariasis due to Dirofilaria (Nochtiella) repens: a review of world literature. Parassitologia 37: 148-191.

15. Perez-Sanchez, R., Gomez-Bautista, M. and Grands, A. E. 1989. Canine filariasis in Salamanca (northwest Spain). Ann. Trop. Med. Parasit. 83: 143-150.

16. Peribanez, A. M., Javier, L., Sergio, A., Mariano, M., Juan, A., Castillo, M. and Gracia, J. 2001. Histochemical differentiation of Dirofilaria immitis, Dirofilaria repens and Acanthocheilonema dracunculoides microfilariae by staining with a commercial kit, Leucognost-SP ${ }^{\circledR}$. Vet. Parasitol. 102: 173-175.

17. Rim, H. J. 1976. A case of human infection with Dirofilaria (Nochitella) species. Korean J. Parasitol. 14: 164 (in Korean).

18. Smith, J. M. 1995. Rare, new and emerging helminth zoonoses. Adv. Parasitol. 36: 19-40.

19. Tarello, W. 2002. Dermatitis associated with Dirofilaria (Nochtiella) repens microfilariae in dogs from central Italy. Acta Vet. Hung. 50: 63-78.

20. Vakalis, N., Spanakos, G., Patsoula, E. and Vamvakopoulos, N. C. 1999. Improved detection of Dirofilaria repens DNA by direct polymerase chain reaction. Parasitol. Int. 48: 145-150. 